\title{
An embedded human rights logic? A comparative study of International Baccalaureate schools in different contexts
}

\author{
Karen Parish ${ }^{1}$ (D)
}

Accepted: 1 May 2021 / Published online: 23 July 2021

(C) The Author(s) 2021

\begin{abstract}
This article presents findings from a study that investigated how the global logic of human rights, as incorporated by the International Baccalaureate schools into their policies and practices, is experienced and adhered to by students who are following the International Baccalaureate Diploma Programme (IBDP) in different contexts. In this study, the cases for comparison were a private school in Norway and a state-funded school in Poland. Although selected for their differences, they offered functional equivalence in the standardized diploma program. The study used a multiple-methods approach, including both quantitative and qualitative data. Findings reveal significant differences between students' levels of adherence to human rights logic. Reasons for this difference point both to logic hybridity within the school organization and a diverse school learning community.
\end{abstract}

Keywords Human rights education - Institutional logics · Comparative education · International Baccalaureate Organisation

Although not a new phenomenon, the elevation of human rights to the international level began during World War I, with human rights invoked as a rationale for fighting "for all humanity to preserve human rights for generations to come" (Clapham 2015, p. 28; prior examples include Hammerabi's code in ancient Babylon, the Greek stoics, the Roman law jus gentium, the American Declaration of Independence, and the French declaration of the Rights of Man and of the Citizen). With the establishment of the League of Nations and associated treaties, efforts were made to protect the rights of specific groups of people (e.g., minorities, workers, and slaves) at the international level. Following the horrors of World War II and building on President Franklin Roosevelt's speech about the four essential human freedoms speech, the Atlantic Charter provided the groundwork for the

Karen Parish

Karen.parish@inn.no

1 Faculty of Education, Inland Norway University of Applied Sciences, Høgskolen i Innlandet, Postboks 400, 2418 Elverum, Norway 
development of modern human rights (Clapham 2015; Glendon 2002). This vision continued with the commitment to universal human rights stated in the United Nations (UN) Charter in 1945, which set in motion the development of the Universal Declaration of Human Rights (UDHR). The UDHR includes a focus on how education can play an important role in the promotion of a universal culture of human rights (Suárez 2007).

Running parallel to these events was the emergence of the field of international schooling. In particular, the development of the international baccalaureate (IB) began with the creation of post-World War I organizations, including the Labour Office in 1919 and the League of Nations in 1920. The employees of the League of Nations opened the International School of Geneva in 1924 to provide for their children. Following World War II, the mobility of expatriate families increased for reasons such as the creation of the UN in 1945, decolonization, the emergence of the United States as a world power, the post-World War II economic boom and international expansion of companies, the Fulbright Act (1964), and technological advances (Hill 2002). During the 1950s, international schools identified problems related to university access, lack of appropriate curricula for internationally mobile students, a need for international understanding, and pragmatic concerns related to the organization of students (p. 193). The IB was developed to address these pragmatic concerns of international schools, which in themselves tended to be elite. However, the founding of the IB was also to some extent built on the human rights ideals formulated in the UDHR (Hill 2002). From the start, the IB faced tensions related to the practical demands for producing a mobile diploma and the "global dreams" of the founders (Tarc 2009a).

Since the 1950s, the IB has grown into a global organization offering an international curriculum spanning the 3 through 19 age range and culminating in the IBDP, with a sub-brand identity for the four programs (Bunnell et al. 2017). With an overall focus on the quality of the global brand, the specific focus of the IB in recent years has been on financial and organizational measures of efficiency and cost-effectiveness, following the advice of international management consultants (Tarc 2009a).

The IB programs of study are found in a wide range of countries and different school types, including traditional international schools and state-funded national schools (Hayden and Thompson 2013). The number of IB programs offered worldwide is increasing rapidly; between 2011 and 2017, the number of IB programs offered worldwide grew by $45.8 \%$ (Gardner-McTaggart 2016; Weenink 2009). As of July 2020, there were 7,002 IB programs offered worldwide, across 4,783 schools (IBO 2021b). An IB education has become synonymous with elitism, as students must either compete academically for a place or provide the financial capital for such an education (Brown 2000; Gardner-McTaggart 2016; Weenink 2009). However, at the core of the IB mission statement, human-rights-promoting ideals persist "to develop inquiring, knowledgeable and caring young people who help to create a better and more peaceful world through intercultural understanding and respect" (IBO 2021c).

This article starts with this ongoing mission; it aims to investigate if and how the global logic of human rights, as incorporated by IB schools into their policies and practices, is experienced and adhered to by students who are following the IBDP in different contexts. The research questions were as follows:

1. Did students' adherence to the human rights logic of the IB differ, depending on context?

2. If school context did make a difference, why? 
These questions will be addressed in this article in the following way. First, a review of the literature will expose the need for further research that explores student human rights competence in IB schools, and in particular, through a comparative lens. Second, the article presents the theoretical approach adopted by the author. The multiple-methods approach and findings are elaborated in two sections: phase 1 and phase 2. In conclusion, the study reveals that despite a global logic of human rights within the IB organization, logic hybridity within the school organization and the diversity of the school learning community (SLC) have an impact on the level of student human rights competence in different contexts.

\section{Review of the literature}

The IB has emerged as a powerful brand with the "programs offered being regarded by many as offering an effective mix of progressive educational approaches and academic rigour" (Wright et al. 2016, p. 4). The expansion can be seen "as a free market response to a global need" for international education (Cambridge and Thompson 2004). In his review of the changing landscape of international education, Bunnell (2020) explored the transition between what he called the first and second phases of growth and development. In particular, he highlighted the market orientation of international education with its supply (profitdriven, liberalization) and demand (market-driven, globalization) forces at work (p. 765). The increased market orientation of international education raises questions about the ideological-driven mission of schools. In particular, are IB schools with idealistic intentions compromised by the ownership and funding of the school (Hayden and Thompson 2018)?

Studies that focus on the IB in particular have highlighted the inconsistencies that exist within the organization between human-rights-promoting ideals and more pragmatic/ instrumentalist concerns (Cambridge and Thompson 2004; Pearce 2013; Simandiraki 2005; Tarc 2009a). Cambridge and Thompson and Cambridge (2002) discussed the tension between the internationalist, more progressive aims of the IB in promoting intercultural understanding and responsible world citizens and the globalist aims that run in line with economic globalism and offer transferable educational qualifications. This dichotomy was also evident in the study by Simandiraki (2005), which explored the internationalist and globalist student identities found in IB schools. Tarc (2009a), in his historical account, examined how the global dreams of the founders of the IB and the practical demands for producing a mobile diploma produced a set of structuring tensions that have endured, albeit with altered dynamics. This tension was also elaborated on as the dualism of equity versus elitism, as the promotion of global citizens in the IB is at odds with the provision of an elite education that offers its students distinction in the global marketplace (GardnerMcTaggart 2016). Schools do not generally fall into one category or the other but rather are on a spectrum and are neither ideologically driven / internationalist or market driven / globalist (Bunnell 2014). The exception to this may be the United World Colleges, which exist to fulfill an ideological dream (United World Colleges 2021).

Gardner-McTaggart (2018), in his research on directors of IB schools, argued that with a clear market-orientation, international schools are orientated to the demographic of a new local market of students heading to universities predominantly in the United Kingdom and United States. These schools are concerned less with idealistic notions of global citizenship and more with the instrumental needs of the upwardly mobile global class (p. 110). In addition, he explored the role that school directors play in the implementation of the 
IB, arguing that there can be a decoupling from the IB organization and its mission aims (Gardner-McTaggart 2019a, b). If the implementation of the IB is left completely to the discretion of the school director, then what is in place to safeguard the human-rights-promoting ideals of the IB?

In addition, part of the ongoing discussion regarding the growth of the IB is the growing disparity between IB activity in high- and low-income countries (Bunnell 2016, p. 192), despite "the IB's commitment to creating a collaborative global community united by a mission to make a better world through education" (IBO 2013, p. 1). Although international schools traditionally existed as community services for expatriate populations, they now are revenue-oriented institutions used by local parents for climbing global education hierarchies (Kim and Mobrand 2019). Many IB schools, particularly in the Asia-Pacific region, operate in the private international schooling sector and charge high tuition fees. This restricts the tuition-charging schools to students from high socioeconomic backgrounds, and at the same time, limits exposure for students who come from other sociocultural backgrounds (Wright et al. 2016). The market-orientation of international school is also evidenced by the growth of large for-profit operators, such as GEMS Education, Cognita, and Nord Anglia, with 142,000, 30,000, and 20,000 students, respectively (Kim and Mobrand 2019). Each of these three firms had annual revenues in recent years between US\$300 and \$500 million (Kim 2016). School groups such as these aim to attract not just expatriates in the same area but anyone who can afford their fees.

However, some studies have explored how IB schools do promote human-rights-promoting ideals. From the literature, it is apparent that the human-rights-promoting ideals of the IB were discussed using different frames of reference (e.g., the terms international mindedness and intercultural understanding). The human rights ideals were also discussed in terms of changing attitudes toward the fulfillment of the IB mission's aims and the IB learner profile. In their study on the attitudes of students enrolled in the IBDP in different contexts, Wilkinson and Hayden (2010) found changes over time as students moved toward the IB mission's aims. Aspects of the school environment that contributed toward this change were informal discussions with teachers and other students and the Theory of Knowledge (TOK) course (p. 95). The IBDP was also credited in a comparative study of two schools in the United States with the increased international understanding of students (Hinrichs 2003). A link has also been found between human-rights-related student learning attributes and the IB continuum (Bryant et al. 2016).

However, the IB learner profile has been criticized for being more committed to program design than to developing attributes that help people live in an interconnected world (Plotkin 2013). Research also suggested that the term international mindedness is subject to being used variously and loosely (Cause 2009; Doherty et al. 2009; Skelton 2007). At the same time, due to the vagueness of the term international mindedness and the little accountability that schools have, teachers and administrators struggle to implement it (Gigliotti-Labay 2010). Belal (2017) explored how the concept of international mindedness promotes students' engagement within local communities through the creativity, action, service (CAS) component of the course. Her findings revealed that rather than the IBDP affecting students' engagement in action, the school's diversity develops the attitude of caring and action. However, others have argued that diversity alone is not enough to develop international mindedness; intervention by way of education is also needed (Bennett 2009; Muller 2012).

In their study on the relationship between participation in the IB curricula and certain attributes identified in the IB learner profile, Bryant and colleagues (2016) revealed that caring was less explicitly emphasized in the IBDP curricula, in comparison with other 
attributes stated in the IB learner profile. At the same time, they found evidence to suggest that the focus on attributes such as caring is more likely to be found in the Middle Years Programme (MYP) than in the IBDP, where the focus is more on academics.

Although the IB mission's aims may appear to give priority to the promotion of human rights ideals, the effectiveness of these aims across a range of contexts remains under researched. The following section outlines the theoretical lens adopted by the author.

\section{Theoretical framework}

The theoretical framework of this study was borrowed from the institutional logics perspective, a branch of institutional theory that focuses on how belief systems shape and are shaped by individuals and organizations (Powell and Bromley 2013; Thornton and Ocasio 2013). Within a given organization, such as a school, an individual's response to their experience of a given logic is dependent on the extent to which they adhere to that logic (Pache and Santos 2013). For example, they may act as a novice (new to the logic) or as if they are familiar with the logic or as if they are easily able to identify with the logic. Based on this level of adherence, individuals may respond in different ways within the organization (e.g., ignorance, compliance, resistance) or may combine or compartmentalize multiple logics. The relationship between adherence to a particular logic and the ways in which an individual responds to that logic is moderated by the degree to which an organization experiences logic hybridity. At the organizational level of the school, a certain level of adherence to a particular logic, such as human rights, may be needed to satisfy institutional referents, such as the IB (Bunnell et al. 2016). However, the level of adherence by individuals within the organization may be influenced by concerns that are external to the organization and co-existing/competing logics within the organization.

The author proposes that the human rights ideals of the IB form an institutional logic that has become embedded in the core of the IB (Parish 2018, 2019b; Tarc 2009a). However, the author questions the extent to which this filters down to individual school organizations, and in particular to students. The author adopts the concepts of adherence, experience, and logic hybridity as analytical tools through which to understand how the global human rights logic embedded in the IB affects different local contexts. The following section discusses the methodological approach of the study, before addressing the first of the research questions.

\section{Methodology}

A substantive stance places the theoretical framework of the study at the forefront (Greene 2007). While respecting the integrity of the paradigms, the study seeks to use their different ways of knowing to expand understanding of how human rights logic is experienced and adhered to in different IB school contexts. Therefore, both concepts founded on postpositivism and concepts founded on the social constructionist approach are included in this research design (Kuckartz 2014). This approach to research design has the purpose of expanding the scope of the study, as different methods are used to assess different phenomena (Greene 2007). In so doing, human rights logic is explored as an interplay between global institutions in contradiction and interdependency, organizations in conflict and coordination, and individuals competing and negotiating (Thornton et al. 2012). Phase 1 adopts a quantitative approach, and phase 2 adopts a qualitative approach. 
The study uses a horizontal case study approach to comparison that explores how human rights logic is experienced between different contexts (Bartlett and Vavrus 2016; Vavrus and Bartlett 2006).

\section{Phase 1}

Research question 1. Did students' adherence to the human rights logic of the IB differ depending on context?

\section{Method}

Adherence in this case is taken to mean the level of commitment students have to IB human rights logic. This question was addressed using a quantitative approach to measuring human rights competence development (HRCD) that has been developed and tested by the author (Parish 2019a). IB human rights logic has a particular focus on intercultural understanding and tolerance as a way to counteract discrimination and prejudice, as expressed in the IB mission statement: "The IB aims to develop inquiring, knowledgeable and caring young people who help to create a better and more peaceful world through intercultural understanding and respect" (IBO 2021c).

First, the IB aims for students to "create a better and more peaceful world", implying the need for action (IBO 2021c). Inspired by the work of Ajzen and Fishbein (1975, 1979, 1980), the Scale of Human Rights Attitudes and Behavioural Intentions (HRAB) that was constructed by the author has 24 items using a 7-point Likert scale. The scale has six subscales that measure attitudes toward the following: human rights values (HRV: $M=6.2$, $\mathrm{SD}=0.90$ ), human rights specific behaviors (HRB: $\mathrm{M}=5.6, \mathrm{SD}=0.84$ ), the attitudes of significant others toward those specific behaviors (ASO: $\mathrm{M}=5.6, \mathrm{SD}=0.89$ ), attitudes toward self-efficacy to complete the specific behaviors ( $\mathrm{SE}: \mathrm{M}=5.6, \mathrm{SD}=0.90$ ), attitudes toward the worthwhileness of the specific behaviors (WO: $\mathrm{M}=5.3, \mathrm{SD}=1.06$ ), and the intention to act (IA: $M=4.6, S D=1.02)$. Estimates of internal consistency for the HRAB total are measured by the alpha coefficient 0.79 .

Second, the IB aims to develop "caring young people", for which empathy is necessary (IBO 2008). The author used the Scale of Ethno-cultural Empathy (SEE), developed by Wang et al. (2003), to measure empathy irrespective of ethnicity. This scale has 31 items and uses a 5-point Likert scale. Four factors emerged: empathic feeling and expression (EFE: $\mathrm{M}=4.3, \mathrm{SD}=0.86)$, empathic perspective taking $(\mathrm{EP}: \mathrm{M}=3.4$, $\mathrm{SD}=1.0$ ), acceptance of cultural differences ( $\mathrm{AC}: \mathrm{M}=4.6, \mathrm{SD}=0.89$ ), and empathic awareness (EA: $\mathrm{M}$ $=4.6, \mathrm{SD}=0.99)$. Estimates of internal consistency for the SEE total and subscales are measured by the alpha coefficients, as follows: SEE total: .91, EFE: .89, EP: .75, AC: .73, and EA: .76 (Wang et al. 2003, p. 228). Reliability estimates in a 2-week test-retest revealed the following: SEE total: .76, EFE: .76, EP: .75, AC: .86 and EA: .64 (p. 230).

Third, the Identification with All Humanity Scale (IWAH), as developed by McFarland et al. (2012), was used to measure the extent to which students identify with all human beings as opposed to with those within their local community or those within their nation. This scale has 9 items and uses a 5-point Likert scale. Three sub-scales measure identification with community (IWC), identification with one's own nation (IWN), and identification with all humanity (IWH). The assumption made by this scale is that those who regard all humanity as one in-group should be low in bias against others seen as out-groups. In their 
study across four different groups, McFarland et al. reported means for the 9 items ranging between 2.76 and 4.05 and standard deviations for the whole scale ranged between 3.17 and 7.01 across the four groups. They reported internal consistency alphas across the four groups ranging between .62 and .89 (p. 835).

An electronic survey including the three scales described above and biographical data was distributed to 16 through 19 year-old students enrolled on the IBDP in nine different schools within Norway and Poland $(N=149$; see Parish 2019a).

\section{Participants and procedures}

Data from the following schools were used in this study.

School $1(n=24)$ is a fully funded state school that caters to academically elite students in one of the larger cities in Poland. Students sit an entrance examination in English to compete for places. Although the school originally incorporated the IBDP with a view to providing an international education for expatriate families moving in and out of the area, it had at the time of data collection an entirely Polish student body.

School $2(n=35)$ is a private school located in Norway. The school has an ideological foundation with a commitment to human rights ideals. The school mission statement aims to bring together people, nations, and cultures for peace and a sustainable future. The intake of students is ethnically diverse and inclusive of a range of cultures, religions, and nationalities. Entrance qualification and fee payment are dependent on the context the students come from.

These schools were selected from the larger study because of the significant differences in the student HRCD scores between the two schools (Figure 1; Bartlett and Vavrus 2016). The schools also differed in terms of location, level of ethnic diversity, and type of school; however, they had functional equivalence as the students were following the IBDP with its standardized IB mission statement.

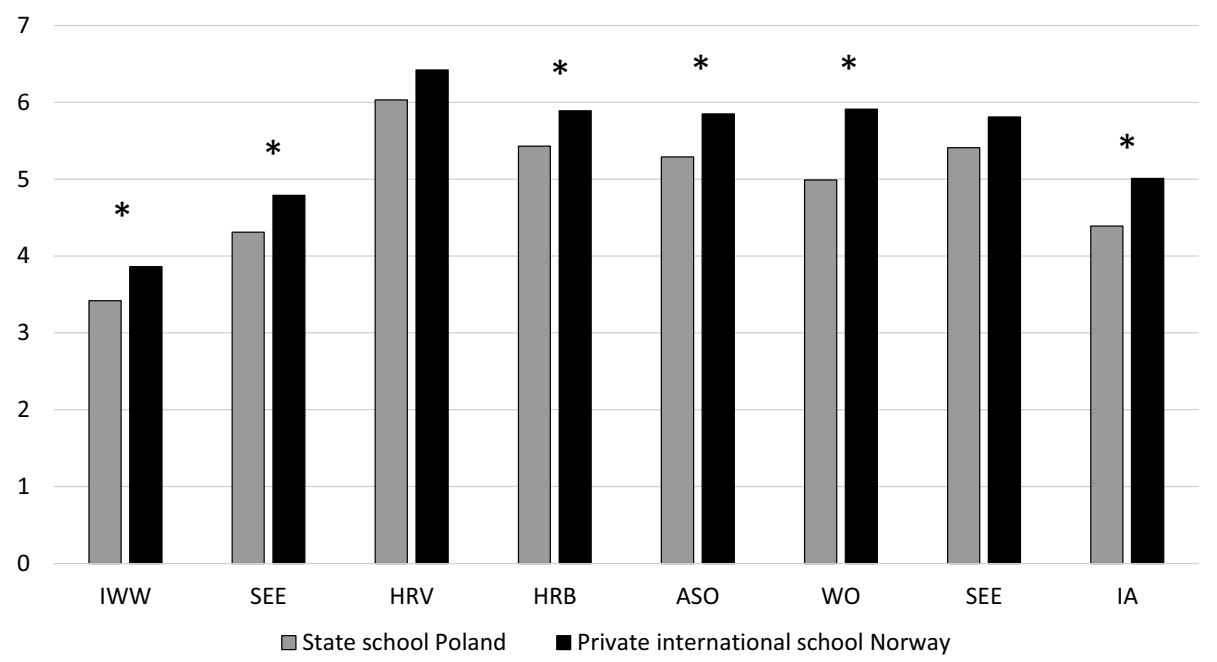

Figure 1 A comparison of the components of the Human Rights Competence Survey between the two cases. 
The mean scores for the SEE, IWAH, and the six sub-scales of the HRAB scale (HRV, HRB, ASO, SE, WO, IA) were calculated, and the scores for both schools were compared using an independent $t$ test in SPSS.

\section{Findings}

Results (Figure 1) showed that students from the private international school in Norway had significantly higher scores for the three components of HRCD than did students from the state-funded school in Poland. The exceptions were with human rights values and selfefficacy (two variables in the HRAB scale), for which the difference was not significant.

The findings from phase 1 of the research revealed, in answer to the research question, that students' adherence to the human rights logic of the IB differed depending on context. Students within the Polish state school had lower HRCD scores, and therefore it could be said that they had lower adherence to the human rights logic of the IB, compared with the students in the international school in Norway. The reasons for this difference in adherence to IB human rights logic are explored in phase 2, as discussed in the next section.

\section{Phase 2}

Research question 2. If school context did make a difference, why?

\section{Method}

Adopting a qualitative approach, semi-structured interviews were conducted with the IB coordinators at each school and a sample of students. The focus of the interviews was on the experiences students had of IB human rights logics in the SLC.

\section{Participants}

IB coordinators are the teacher responsible for the coordination of the IBDP. These individuals are responsible for ensuring that the IB requirements are met within the SLC and for coordination between the IB and the school. Each interview, lasting between 30 and 40 minutes, was recorded and transcribed by the author.

Twelve students from each of the two schools in phase 1 were selected. In each school six boys and six girls were invited to interview. These students were selected to incorporate a range of scores for HRCD to represent varying degrees of adherence to IB human rights logic. The interviews, lasting between 20 and 60 minutes, were recorded and transcribed by the author.

Interviews were analyzed using thematic qualitative text analysis and NVivo 10 (Kuckartz 2014). The analysis drew on Thompson's (1998) notion of interstitial learning in the SLC, by exploring the experiences students had both within and beyond discrete subjects.

\section{Findings}

The findings from phase 2 will be presented as two separate case studies, followed by a comparison between the two (Stake 2013; Vavrus and Bartlett 2012). Each case study will include the following subcategories that emerged from the data analysis. 
- Formal curriculum and specific subjects taken (e.g., mathematics)

- Extracurricular activities that students experienced

- Influence of teachers as role models

- Lived experience of diversity

- Logic hybridity

\section{School 1}

The formal curriculum. School 1 offered the IBDP alongside the Polish equivalent state program of study. Therefore, the staff and students were one SLC with two separate programs of study. The school had no official policy regarding the teaching of or promotion of human rights in their educational programs. The IB requires that at least one subject within each of the six academic learning areas of the IBDP must be offered, ensuring that students have a breadth of subjects (IBO 2021b). However, the subjects offered by the school were selected for pragmatic reasons.

20 years ago English was not as common as it is now. So it was hard to find a Biology or Geography teacher who could teach in English. Last year we were able to add Economics, and next year we have a guy who is coming to teach Global Politics. (IB coordinator; Parish 2018, p. 13)

It also became apparent during the interviews that students selected subjects for pragmatic reasons, either due to interest or because they had very focused ideas of what they would study at university (Parish 2018). Students only experienced IB human rights logic in a limited number of subjects. In certain subjects, particularly within the IBDP academic area of Individuals and Societies, students experienced human rights logic to a greater degree; in particular, geography and history were cited as subjects in which students learned about human rights.

The data also revealed that the experience of students within these subjects was very uneven. Kasia, who opted to study both history and geography, in fact claimed she did not experience human rights learning in the school. She stated, "Not at all. Maybe psychology, but I am not taking that" (Parish 2018, p. 13). An understanding of what was meant by human rights content was established at the beginning of the interview; therefore, this was not just a case of different understandings about how to define human rights content in lessons. Kasia did not have the same experience of geography as, for example, Marcin, who stated, "For me it is easy to see because I have taken geography which is connected to human rights. We try to find solutions to some problems, water shortages, honor killings in some countries". The variation between subjects was hardly surprising, because subjects such as geography and history lend themselves to human rights content far more than do subjects such as math and physics. However, these data suggested that students' experience of human rights logic not only varied between subjects but within subjects as well.

Extracurricular activities. CAS was offered by school 1 as part of the diploma (IBO 2021a). While CAS was not one of the six academic study areas examined, it was a required component of the IBDP. The model UN is an example of how human rights were promoted within the CAS component. "We have a long tradition of simulating the UN debate and it is a big event every year for which students prepare themselves" (IB coordinator; Parish 2018, p. 13). However, only three of the 12 students discussed involvement in the model UN as one way in which they learned about and experienced human rights. The IB coordinator also mentioned letter writing for Amnesty 
International to show solidarity with those facing violations of human rights: "Every year we organize this event of writing letters for Amnesty International. It is a huge event. This year we ran short of envelopes because the students were so enthusiastic" (p. 14). However, only two of the 12 students mentioned the Amnesty letter writing as a way in which they experienced human rights in the school. This suggests that either students did not associate these activities with human rights or they did not participate or remember participating. Although the students all had the opportunity to experience the model UN, the Amnesty International letter writing, and project work, they did not necessarily all respond in the same way. Some suggested that not all students responded enthusiastically toward CAS. Kasia said,

There is a possibility [to do activities that promote human rights]. We are supposed to do CAS. We are supposed to do service, help disadvantaged people. Some people in class promote the rights of minorities. We are supposed to choose the way we do CAS. (Parish 2018, p. 15)

Szymon supported this:

It all depends on the person. I think you need to grow up to this point where you decide you want to help people. Some people are not really socializing and step out of their comfort zone and help people. But most people are involved in some way in helping the community. (Parish 2018, p. 15)

Two of the 12 students also referred specifically to a project they were involved in for CAS that reflected a very positive response to the human rights logic of the IB. This was a student-led project with the purpose of creating an online platform for foreigners in the city to tell their story. Syzmon said,

It provides a platform for the humanizing of people. They can be seen as individuals and not just as "foreign". Polish people are not so accepting in most cases and we wanted to show these people that just because someone is different or different colour of skin doesn't make them a bad person or not to be liked. These are people, who may be part of a group, nation or religion, but they are an individual and a real story. (Parish 2018, p. 14)

Those with a particular interest in human rights issues experienced encouragement and support from the school to pursue their interest and responded positively. However, others only did what was required to gain their diploma.

Teacher influence. When asked if they felt that teachers in the school influenced their attitudes toward human rights and in particular their attitudes toward those who are ethnically different, students' answers were mixed. Some said the IB teachers influenced them positively. For example, Natalia said, "I can't think of any specific teacher, they all influence me in a good way" (Parish 2018, p. 15). In particular, the geography teacher was discussed as having had a particular influence:

I think that our geography teacher as we are looking at all the issues from very different perspectives. When we think about the issues of the Middle East we think from our own European perspective, but for these people who are born there then it is normal, a different mentality. He tries to help us to see this different perspective. (Kamil; Parish 2018, p. 15) 
One student also mentioned that the IB coordinator was the person who "tells us the reality and how to avoid stereotypes" (Julia; p. 15). So although teachers did have an influence in some cases, this was not true for all students interviewed.

Lived experience of diversity. The school is $100 \%$ Polish in what remains an ethnically homogenous society. The IB coordinator stated, "Human rights education I would say is sensitizing students to legal and political issues around them which in our case is mostly theoretical as I think we live in a country where most of the rights are observed" (IB coordinator, school 1). Students also made the point that much of what they learned about human rights was from a textbook, especially when it came to ethnic diversity and rights. Their experiences of diversity largely come from elsewhere, including very positive experiences of ethnic diversity within their family. Szymon said,

The community you grow up in. I lived on the border and was always related to another community. There was the Polish community and the German community and a lot of stereotypes. In school we did a lot of projects in cooperation with German students and from the Czech Republic. It is not like they are all super different nations and of course we differed. (Parish 2018, p. 16)

For some, the media had promoted positive attitudes of the ethnic other. For others, though, the negative experience of diversity from the media had an impact.

I think always it is from the media as in Poland we don't have immigrants and different religions. On $\mathrm{CNN}$ and $\mathrm{BBC}$ news and YouTube there are many videos showing people fighting, or there are articles showing a woman has been raped. I don't really know what to believe or where the truth is. (Julia; Parish 2018 p. 16)

Some who had experienced discrimination in other areas of their life felt they could empathize with others who were different. The data reflected the varied experiences of students outside the SLC as affecting their attitudes toward the human rights logic of the IB.

Logic hybridity. A tension between human rights logic and more pragmatic concerns emerged from the data. It became clear from each of the students interviewed that their primary purpose in joining the IBDP was to gain a good qualification that is internationally recognized. Their ambitions, to a large extent, involved university study in another country and a good job. The IB coordinator acknowledged that while, for her, the human rights logic of the school was essential and made the IBDP special, at the same time, the school was preparing students to go out into the world to pursue their dreams (Parish 2018). The school achieved very good examination results, and the IB coordinator was keen to maintain their "top scores in the city". She summed up the motivation of the IBDP students: "When I look at them, the IB students work so much harder, they spend the whole day here. Sometimes they come in at $7 \mathrm{am}$ and leave at $6 \mathrm{pm}$. They look and are tired". (Parish 2018, p. 17)

One student summarized the sentiments of all 12 of the interviewees when she said,

The IB as a program is a great thing as it encourages thinking and develops ourselves. But we can't forget that we are doing it to promote ourselves to make ourselves a good valuable, to sell to universities and get a good job and so on. (Ola; Parish 2018, p. 17)

It was apparent in this particular school that the IBDP acts as a form of differentiation within the national education system of Poland. It not only provides the students with a more challenging internationally recognized program of study but also a learning 
community whose student body is made up of like-minded and equally motivated student peers. This revealed a very pragmatic logic, which was expressed by the IB coordinator:

I would think that the specific situation that we have here is not typical of other IB schools, in the fact that we select the students through the exam. This guarantees us better student material. When we look at the results the average IBDP point score in the world is 29 and we have an average of 37 points.

\section{School 2}

The formal curriculum. School 2 offered the IBDP exclusively as a program of study. As with all schools offering the IBDP, the IB requires at least one subject within each of the six academic learning areas. The subjects offered by school 2 were very broad and the IB coordinator did not refer to any pragmatic reasons for this selection. School 2 also offered, in addition to the IBDP, something called Life Skills, which focused on the school's values. The IB coordinator stated that human rights ideals are "In our student charter. We have consideration and respect for others that is something that we keep on harking on about". The students discussed experiencing human rights in particular subjects, such as global politics, geography, history, and philosophy. These were part of the Individuals and Societies group of the IBDP. For example, Caroline said,

In geography which covers all of human behaviors. Often we have these discussions about what are the problems and then we have 5 minutes to come up with a solution and I think we have so many smart leaders who get huge bunches of money and it is their job to find solutions and they just haven't. And we have certain problems for years now and solutions haven't been found and I feel that just a bit helpless when they ask me with my four other people to come up with a solution to this major complex problem that I probably don't even understand half of it. There are so many layers of problems there.

Although Caroline revealed a sense of helplessness in the way in which human rights issues were experienced in geography class, she did acknowledge that human rights were included in the subject.

Another subject in which students experienced human rights content was global politics. "Global politics for sure. We have four core units and one of them is Human Rights. So one quarter of the syllabus is human rights focused" (Melissa). However, other subjects were also cited as containing human rights content. For example, "In English literature we have been studying indigenous poetry and that made us look into the contexts of the poets" (Melissa). The school also offered Environmental Systems and Societies, a transdisciplinary course that included global human rights content. Philosophy, English, and Norwegian literature were also cited as subjects in which students discussed human rights.

I guess it really depends on which subjects you take. If you take global politics then it is like poof everything is about human rights. They even have this book that is really thick that is just about human rights. If you take History you will also touch a bit about human rights. basically if you take the humanities subjects but in the other subjects then not so much. (Andrew)

Andrew summed up the experiences of human rights in specific subjects. The extent to which a student experienced human rights in classes very much depended on the subject. 
Extracurricular activities. CAS was offered by school 2 as part of the diploma. Although CAS was not one of the six academic study areas examined, it was a required component of the IBDP. The expectation was that students would involve themselves in these activities, as explained by Jennifer:

I think that it is not so much what we do in specific subjects, but more what we do outside of the academic. We have a lot of extra activities that we have to do outside of classes and that is where I think the human rights comes in the most.

Caroline explained how one activity had an impact on her in particular:

So we did a refugee simulation where were 24 hours out in the forest walking and we only got $23 \mathrm{~g}$ of rice. I guess it was an attempt to understand the feeling of being are a refugee. But you cannot compare what we did with actual fear. It's a glimpse and in that sense this school tries to push human rights a lot.

Although there was a certain degree of choice of activities within the CAS program, the school also has specific days committed to global concerns. These days were compulsory for all students and had a focus on human rights, as Daniel explained:

Yesterday we had global concerns day and the last one we had focused on human rights. The last one which I helped organize focused on migration and the crisis in Europe and you can clearly see ties with human rights. Yesterday it focused on the innocent victims of conflict and human rights abuses came out of conflict. There are also NGOs Rafter, and Amnesty International. These are optional. It is variable depending on the student, but I think the overwhelming majority engage with deep interest. As with any academic community you have a small number of students who do not commit fully to anything or everything.

So while the experiences and responses to extracurricular activities varied from student to student, the school did offer a varied extracurricular program.

Teacher influence. When students were asked if they felt that teachers in the school influenced their attitudes toward human rights, and in particular their attitudes toward those who are ethnically different, they were very positive. As Jennifer indicated: "I have only been here 3 months and there are things teachers have said to me that have stuck with me in my mind and my heart". Most of the students interviewed mentioned the role of teachers as mentors or supervisors as being influential. For example: "We have a great system here where aside from subject teachers you have mentors who help you both language wise and life wise. They have been a huge help and a positive influence" (Elizabeth).

Yeah, I would definitely say there are some teachers you get inspired by. The development studies teacher he is basically talking all the time about cultures and everything. And more personally my advisor who is a math teacher. Maybe I have been lucky with my teachers and advisors and mentors. (Andrew)

Another example of this is the geography teacher, who was considered by most of the students to be influential, even by students who were not taking geography as a class. Melissa summed up how he had influenced her: "In a way ..., he really opened my eyes when it comes to understanding different cultures in like every situation".

Lived experience of diversity. In school 2, the diversity within the student population represented 95 nations. The scope of those represented was far-reaching and inclusive of nations from east and west, north and south. The student population also represented a wide range in terms of socioeconomic status. Some students came from 
wealthy families who were paying fees. Other students came from impoverished war zones and were on student scholarships. The student body also represented a range of academic abilities. Some students were in the top $30 \%$ of their previous school systems and were fluent in English. Other students had experienced limited education and came to the school with very limited English language skills. The school accommodated this academic diversity by offering a 1-year foundation program students can complete before they begin the IBDP. This allows them to improve their English and learn study skills.

All of the students cited their experience of diversity in the SLC as having had a positive influence on their attitudes toward those who are ethnically different. For example, Jennifer said,

I think the school has a lot to do with it because you are surrounded by many different people and everyone accepts each other so you have this sense that you have to have a really positive attitude to everyone being different.

Caroline also pointed to the social aspect of the school as a big influence: "My experiences just by talking to people and meeting people and getting a connection to people. I think my experience of being here has mostly influenced me". However, some students felt that they were influenced by the media and family. For example, Jennifer attributed her positive attitudes to diversity not only to the school but also to family: "I think it is because my parents are very open about it and a lot of my cousins have gone to Southeast Asia and they are married. I have cousins from Southeast Asia and we are very open about this".

Logic hybridity. Because they attended a school that offered the IBDP, students were encouraged and supported to fulfill their academic potential. However, academic success did not appear to be a priority for the school, as emphasized by the IB coordinator: "We don't have to play any kind of results, league figure games at all". The ideals of school 2's mission statement helped to create the identity of the SLC. These ideals promoted intercultural understanding, tolerance, and working for a better world. For example, this was reflected in the way students were selected for a place in the school.

We have a significant travel support program so it is possible for students, survivors of conflict, from South Sudan, Mozambique, Angola, poor countries to come. Their financial means is irrelevant so for such a student this is a huge opportunity to get an education where they are provided with materials, and decent classrooms and qualified teachers. (IB coordinator)

However, the IB coordinator also said that they attracted students who were "enthusiastic or keen to do something and they tend to be quite hard on themselves and we have more than our share of perfectionists. So it is a really mixed bag".

The data also revealed that students did not feel that the priority of the school was to accomplish high grades. For example, Daniel remarked,

You do have a stronger sense of community and also a bit more of a broader scope about working towards community projects and making a difference, whereas a normal International school may just be focused on pumping out $45 \mathrm{~s}$ in the IBDP.

So while it can be argued that both the more pragmatic concerns of studying for the diploma existed within school 2, this appeared to be very much balanced with the human rights logic promoted by the IB. 


\section{Summary}

The two case studies elaborated on the findings from the interviews conducted. The discussion in the following section will explore differences between the two schools that could illuminate why students in the two schools had significantly different HRCD scores and levels of adherence to IB human rights logic.

\section{Discussion}

A comparison between the two schools in phase 1 revealed that students' adherence to the human rights logic of the IB did differ depending on context (Figure 1). Individual case studies of the experiences of students and IB coordinators in each of the two schools also revealed differences within the school learning communities. This section will discuss the similarities and differences between the two school learning communities, focusing on each of the five areas discussed in the individual case studies.

\section{Formal curriculum}

In both schools, the experiences students had of human rights in the formal curriculum very much depended on which subjects students opted to study. In both schools, the subjects that were part of the Individuals and Societies group offered the most humanrights-related content. However, the students in school 2 seemed to have a more consistent experience of human rights. For example, the students who studied geography in school 2 all experienced human rights content in their lessons, compared with in school 1 , where students taking the same subject seemed to have had different experiences. At the same time, school 2 offered additional subjects to those of school 1. For example, school 2 offered environmental systems and societies, global politics, and philosophy. These subjects, in particular global politics, lend themselves to human rights content. Students in school 2 also appeared to have experienced human rights content in subjects that were not part of the Individuals and Societies group (e.g., English and Norwegian literature). This did not appear to be the case in school 1 . What was apparent in both school contexts was that the degree to which a student experienced the human rights logic of the IB in discrete subjects depended on the subjects opted for by students.

\section{Extracurricular}

Although both schools offered the compulsory CAS program and a range of activities, what was striking in the data was the greater variety of extracurricular activities offered in school 2. School 2 had a strong focus on human-rights-promoting activities, such as the global issues days, the refugee simulation, and humanitarian aid projects. Also, there appeared to be a greater expectation that students would participate. However, in 
school 1, although students had the opportunity to engage in activism and projects, this was to a large extent left to the discretion of the students and their particular interests.

\section{Teacher influence}

The students from school 1 had rather mixed opinions about the extent to which teachers influenced their attitudes toward human rights, and in particular, those who are ethnically different from them. Although some teachers, such as the geography teacher, were cited as being influential, this was only mentioned by a couple of students. However, school 2 had much more uniformity in the responses given. Each of the students interviewed, even those who had only arrived at the school a few months before, felt that the teachers influenced them in a positive way. However, it was the role of teachers as mentors in school 2 that was the most strikingly different. In school 2, the pastoral role of teachers as mentors played an important part in developing students' attitudes. Also, the emphasis placed on extracurricular activities where teachers were involved lent itself to students being influenced by teachers from subjects they did not themselves take. For example, the geography teacher in school 2 was influential to students who did not take geography, as he was actively involved in extracurricular activities. This influence from teachers outside specific classes was not evident in school 1; the exception to this was that one of the students mentioned the IB coordinator as being influential in how they perceived those who are ethnically different.

\section{Lived experience}

The difference between the two schools was most striking when we consider the lived experience students had of diversity. The homogenous school community in Poland did not afford students the opportunity to relate to people who are ethnically different from themselves. Instead, their only experiences, if any, of diversity came from beyond school-for example, through the media and family. One student had experienced diversity in the community he grew up in. However, in school 2, although there were influences from outside the school, the students were all in agreement that the diversity within the school had a big impact on the formation of their attitudes toward those who are ethnically different. At a school with such diversity, the students had to develop the ability to work together, which involved perspective taking and learning to be tolerant. At the same time, the teachers, mentors, and school leadership also needed to work to help students develop these skills. This appeared to have played a big part in the development of empathic perspective taking and identification with all humanity, components of HRCD assessed in phase 1. Diversity was also found to play a crucial role in the promotion of positive attitudes toward the IB mission statement in the work of Lineham (2013). Other scholars argued exposure to diversity is more important than any particular program of study (Hayden and Thompson 1998; van Oord 2007).

\section{Logic hybridity}

The data revealed a marked difference between the two schools in terms of the emphasis placed on the human rights logic of the IB. In the SLC in Poland, human rights logic appeared to compete with the more pragmatic concerns of academic success in terms of 
high IBDP scores, university entrance, and a good job. Although students may experience the human rights logic of the IB in school, the focus was more on these pragmatic concerns. This logic hybridity within the SLC could be a reflection of the school itself and the values enshrined in the school. It could also be that logic hybridity exists in the IB program within the school due to the logic hybridity that exists in the IB as an organization. This has been supported by research into the ongoing tensions within the IB (Cambridge and Thompson 2004; Pearce 2013; Simandiraki 2005; Tarc 2009a). In addition, it has been supported by research suggesting that IB schools are on a spectrum and are neither ideologically driven / internationalist or market driven / globalist (Bunnell 2014). However, in school 2, the demands of the IBDP were balanced with the perceived value of living in a diverse community. For some students, the experience of being in a diverse learning community was prioritized over academic success, to the point that not all students take the diploma. For others, the drive to succeed academically was balanced with concerns for human rights ideals. Therefore, it can be argued that there was logic hybridity in both schools. Both supported the human rights logic of the IB and what could be called pragmatic logic. However, school 1 appeared to prioritize pragmatic logic over human rights logic, whereas it could be argued that school 2 did not appear to prioritize one logic over the other. The priorities afforded by the schools had an impact on both the experiences of the students and the responses of the students to IB human rights logic. This suggests that the focus on human rights ideals may have had more to do with the school itself than the IB as an organization. School 2 had an ideological foundation with a commitment to human rights ideals. It was purposively diverse both in terms of students and teachers. However, school 1 offered the IBDP to a select group of students to cater to academically elite students. Although school 1 might incorporate some of the human rights ideals into the SLC, that was not the main purpose of offering the IBDP to students.

\section{Conclusion}

What emerged from this research is that the SLC does play a role in influencing students' levels of adherence to human rights logic. The following findings emerged. First, the competition between IB human rights logic and a more pragmatic logic that focuses on exam success emerged as an explanation for the difference. The focus in the Polish school, both at an organizational level and at the level of individual students, was very much on internationally recognized qualifications, in the English language, as a way for students to promote themselves globally and improve their marketplace value (Gardner-McTaggart 2016, 2018; Kim and Mobrand 2019). However, to get authorization and legitimacy from the IB, the school must offer CAS and TOK courses and be seen as promoting human rights ideals (Bunnell et al. 2016). Therefore, it can be argued that the school experiences logic hybridity, as supported by the broader literature that explored this tension (Cambridge and Thompson 2004; Gardner-McTaggart 2016, 2018; Tarc 2009a, 2019). This moderated the ways in which students experience and respond to human rights logic (Pache and Santos 2013). However, the private school in Norway, while adhering to both the pragmatic and human rights logics of the IB, did not prioritize one over the other. Second, diversity within the SLC led to the necessity of intercultural understanding more than it did in a context with a homogenous student population (Yemini and Dvir 2016). Finally, some students were strongly influenced by factors external to the SLC, including family, media, and past experiences (DiMaggio and Powell 1983; Pache and Santos 2013). 
These findings led the author to question the motivations of the IB as an organization. It is clear from the research that historically there has been tension between human-rightspromoting ideals and the more pragmatic/instrumentalist concerns of the IB (Cambridge and Thompson 2004; Pearce 2013; Simandiraki 2005; Tarc 2009a). However, is the IB going far enough to promote and safeguard its human rights logic or is it focused too much on the pragmatic concerns of academic qualifications, and in turn, on students' future success in the global economy (Gardner-McTaggart 2018; Kim and Mobrand 2019; Tarc 2009b)? This question should also be considered in light of competition between schools to attract the best students, and the focus of the IB on financial and organizational measures of efficiency and cost-effectiveness (Bunnell 2020; Tarc 2009a).

When it comes to human rights, both schools did not receive strong guidance from the IB on how to promote human rights. Although the potential for human rights promotion may be implicit in the CAS program and some of the discrete subjects offered, it was largely left to the discretion of the school and teachers to decide how to implement this. Therefore, a school such as the private school in Norway, with its ideological humanrights-promoting heritage, was in a strong position to promote IB human rights logic. However, a state-funded school in Poland was left to find its own resources with respect to how to handle IB's competing logics of human rights ideals and pragmatic concerns (Tarc 2009a). What emerged was a need for closer investigation of how IB schools are set up and authorized and how the IB provides training and support to fulfill its mission. What are the priorities of the IB: human rights or increased revenue in the global market (Bunnell 2020)?

At the same time, one must consider the students enrolled in the IBDP. For many, this was their first experience of IB programs of study. Many were educated prior to the IBDP in other educational systems. Therefore, one might question if it was too little too late? Was it too much to expect a school to develop students' adherence to the human rights logic of the IB at the age of 16 and within 2 years? Further investigation is needed to explore how and why individuals develop adherence to a particular logic. Why do some students begin the IBDP already identified with human rights logic, while others appear only to be familiar with the logic after 5 years of IB schooling? The findings hint at reasons for this within the broader social context, such as family, community and media, but further investigation is needed (DiMaggio and Powell 1983; Pache and Santos 2013).

The study was limited in its scope because the students who participated did not necessarily represent their school populations. Both schools had approximately 200 IBDP students enrolled. Therefore, only a relatively small proportion of students participated in the research (less than 25\%), and the findings cannot be generalized beyond the two participating schools. The author suggests that further study on a larger scale exploring the extent of variation in IBDP students' HRCD and the reasons for this would be beneficial. In particular, it would be interesting to explore how the human-rights-promoting ideals of the IB are implemented in for-profit schools with high students fees (Wright et al. 2016). How can human rights be taught in an emancipatory way when the subject is taught in a context of advantage and privilege?

A further limitation of this study is that it took a snapshot at one point in time rather than focusing on how an individual's adherence to a particular logic evolved over time (Wilkinson and Hayden 2010). Identifying if a prolonged period of time in an IB school develops greater adherence to human rights logic would help to gain a better understanding of how much impact IB schools have on promoting human rights logic.

However, by investigating through the lens of institutional logic how the global logic of human rights is experienced and adhered to by students who are following the IBDP in 
different contexts, this study contributes to new knowledge about the complexity of relationships between individuals and their institutional environment. Simply because students attend a school that is part of a global organization in which human rights logic is apparently embedded does not mean they will adhere to it.

Open Access This article is licensed under a Creative Commons Attribution 4.0 International License, which permits use, sharing, adaptation, distribution and reproduction in any medium or format, as long as you give appropriate credit to the original author(s) and the source, provide a link to the Creative Commons licence, and indicate if changes were made. The images or other third party material in this article are included in the article's Creative Commons licence, unless indicated otherwise in a credit line to the material. If material is not included in the article's Creative Commons licence and your intended use is not permitted by statutory regulation or exceeds the permitted use, you will need to obtain permission directly from the copyright holder. To view a copy of this licence, visit http://creativecommons.org/licenses/by/4.0/.

\section{References}

Bartlett, L., \& Vavrus, F. (2016). Rethinking case study research: A comparative approach. Oxford: Routledge.

Belal, S. (2017). Participating in the International Baccalaureate Diploma Programme: Developing international mindedness and engagement with local communities. Journal of Research in International Education, 16(1), 18-35.

Bennett, M. J. (2009). Defining, measuring, and facilitating intercultural learning: A conceptual introduction to the intercultural education double supplement. Intercultural Education, 20(Sup1), S1-S13.

Brown, P. (2000). The globalisation of positional competition? Sociology, 34(4), 633-653.

Bryant, D. A., Walker, A., \& Lee, M. (2016). A review of the linkage between student participation in the International Baccalaureate Continuum and student learning attributes. Journal of Research in International Education, 15(2), 87-105.

Bunnell, T. (2020). The continuous growth and development of 'International Schooling': The notion of a 'transitionary phase'. Compare: A Journal of Comparative and International Education, 50(5), 764-768.

Bunnell, T., Fertig, M., \& James, C. (2016). What is international about International Schools? An institutional legitimacy perspective. Oxford Review of Education, 42(4), 408-423.

Bunnell, T. (2014). The changing landscape of international schooling: Implications for theory and practice. Oxford, England: Routledge.

Bunnell, T. (2016). The dearth of International Baccalaureate schools across Africa. Africa Education Review, 13(2), 181-195.

Bunnell, T., Fertig, M., \& James, C. (2017). The institutionalisation of teachers and the implications for teacher identity: The case of teachers in International Baccalaureate 'World Schools'. In Paper presented at the annual conference of European conference on educational research, Copenhagen, Denmark, Copenhagen, Denmark. http://opus.bath.ac.uk/56966/3/ECER_2017.pdf.

Cambridge, J. (2002). Global product branding and international education. Journal of Research in International Education, 1(2), 227-243.

Cambridge, J., \& Thompson, J. (2004). Internationalism and globalization as contexts for international education. Compare, 34(2), 161-175.

Cause, L. (2009). International mindedness and 'social control'. Asian Social Science, 5(9), 32.

Clapham, A. (2015). Human rights: A very short introduction. Oxford: Oxford University Press.

DiMaggio, P. J., \& Powell, W. W. (1983). The iron cage revisited: Institutional isomorphism and collective rationality in organizational fields. American Sociological Review, 48(2), 147-160. https://doi.org/10. 2307/2095101.

Doherty, C., Mu, L., \& Shield, P. (2009). Planning mobile futures: The border artistry of International Baccalaureate Diploma choosers. British Journal of Sociology of Education, 30(6), 757-771.

Fishbein, M. (1979). A theory of reasoned action: Some applications and implications. Nebraska Symposium on Motivation, 27, 65-116.

Fishbein, M., \& Ajzen, I. (1975). Belief, attitude, intention and behavior: An introduction to theory and research. Boston, MA: Addison-Wesley.

Fishbein, M., \& Ajzen, I. (1980). Understanding attitudes and predicting social behavior. Upper Saddle River, NJ: Prentice Hall. 
Gardner-McTaggart, A. (2016). International elite, or global citizens? Equity, distinction and power: The International Baccalaureate and the rise of the South. Globalisation, Societies and Education, 14(1), 1-29.

Gardner-McTaggart, A. (2018). The promise of advantage: Englishness in IB international schools. Perspectives: Policy and Practice in Higher Education, 22(4), 109-114.

Gardner-McTaggart, A. (2019a). International schools' leadership and Christianity. Globalisation, Societies and Education, 17(4), 458-473.

Gardner-McTaggart, A. (2019b). Leadership of international schools and the International Baccalaureate learner profile. Educational Management Administration \& Leadership, 47(5), 766-784.

Gigliotti-Labay, J. (2010). Fulfilling its mission? International mindedness in IB DP programmes [Doctoral dissertation, University of Houston Houston]. https://uh-ir.tdl.org/uh-ir/bitstream/handle/ 10657/180/GIGLIOTTI-LABAY-.pdf?sequence=2

Glendon, M. A. (2002). A world made new: Eleanor Roosevelt and the Universal Declaration of Human Rights. New York, NY: Random House.

Greene, J. C. (2007). Mixed methods in social inquiry (Vol. 9). Hoboken, NJ: Wiley.

Hayden, M. C., \& Thompson, J. (1998). International education: Perceptions of teachers in international schools. International Review of Education, 44(5-6), 549-568.

Hayden, M. C., \& Thompson, J. (2013). International schools: Antecedents, current issues and metaphors for the future. In R. Pearce (Ed.), International education and schools: Moving current issues and metaphors for the future (pp. 3-24). London: A\&C Black.

Hayden, M., \& Thompson, J. (2018). Time for new terminology? International School, 21(1), 1-3.

Hill, I. (2002). The International Baccalaureate policy process in education. Journal of Research in International Education, 1(2), 183-211.

Hinrichs, J. (2003). A comparison of levels of international understanding among students of the International Baccalaureate Diploma and advanced placement programs in the USA. Journal of Research in International Education, 2(3), 331-348.

IBO [International Baccalaureate Organisation] (2008). IB learner profile booklet. http://wcpsmd.com/ sites/default/files/documents/IB_learner_profile_booklet.pdf

IBO (2013). What is and IB education? http://www.ibo.org/globalassets/digital-tookit/brochures/whatis-an-ib-education-en.pdf

IBO (2021a). CAS projects. http://www.ibo.org/programmes/diploma-programme/curriculum/creativityactivity-and-service/cas-projects/

IBO (2021b). Curriculum. http://www.ibo.org/programmes/diploma-programme/curriculum/

IBO (2021c). Mission. http://www.ibo.org/about-the-ib/mission/

Kim, H. (2016). The rise of transnational education corporations in the Asia Pacific. The Asia-Pacific Education Researcher, 25(2), 279-286.

Kim, H., \& Mobrand, E. (2019). Stealth marketisation: How international school policy is quietly challenging education systems in Asia. Globalisation, Societies and Education, 17(3), 310-323.

Kuckartz, U. (2014). Qualitative text analysis: A guide to methods, practice and using software. Thousand Oaks, CA: Sage.

Lineham, R. (2013). Is the International Baccalaureate Diploma Programme effective at delivering the International Baccalaureate mission statement? Journal of Research in International Education, 12(3), 259-282.

McFarland, S., Webb, M., \& Brown, D. (2012). All humanity is my ingroup: A measure and studies of identification with all humanity. Journal of Personality and Social Psychology, 103(5), 830.

Muller, G. C. (2012). Exploring characteristics of international schools that promote international-mindedness [Doctoral dissertation, Columbia University, New York, NY]. https://search.proquest.com/ openview/f2b10d1a6269c08bbc5e772d7e8b22a8/1?pq-origsite=gscholar\&cbl=18750\&diss $=y$

Pache, A.-C., \& Santos, F. (2013). Embedded in hybrid contexts: How individuals in organizations respond to competing institutional logics. Research in the Sociology of Organizations, 39, 3-35.

Parish, K. (2018). Logic hybridity within the International Baccalaureate: The case of a state school in Poland. Journal of Research in International Education, 17(1), 49-66.

Parish, K. (2019a). A measure of human rights competence in students enrolled on the International Baccalaureate Diploma Programme. Oxford Review of Education, 45(3), 390-404.

Parish, K. (2019b). A theoretical approach to understanding the global/local nex-us: The adoption of an institutional logics framework. Nordic Journal of Comparative and International Education (NJCIE), 3(2), 3-19.

Pearce, R. (2013). International education and schools: Moving beyond the first 40 years. London, UK: A\&C Black. 
Plotkin, W. (2013). International mindedness: Sounds good but what is it? In L. P. Stagg (Ed.), International mindedness: Global perspectives for learners and educators (pp. 1-13). Chatham: Urbane Publications.

Powell, W. W., \& Bromley, P. (2013). New institutionalism in the analysis of complex organizations. In J. Wright (Ed.), International encyclopedia of social and behavioral sciences (Vol. 2, pp. 764-769). Amsterdam: Elsevier.

Simandiraki, A. (2005). Of onions and ruins: Knowing cultures through their heritage? International Schools Journal, 24(2), 40.

Skelton, M. (2007). International mindedness and the brain: The difficulties of becoming. In M. C. Hayden, J. Levy, \& J. Thompson (Eds.), The SAGE handbook of research in international education (pp. 379389). New York, NY: Sage.

Stake, R. E. (2013). Multiple case study analysis. New York, NY: Guilford Press.

Suárez, D. (2007). Human rights and curricular policy in Latin America and the Caribbean. Comparative Education Review, 51(3), 329-352. https://doi.org/10.1086/518480.

Tarc, P. (2009a). Global dreams, enduring tensions: International Baccalaureate in a changing world. New York, NY: Peter Lang.

Tarc, P. (2009b). What is the 'International' in the International Baccalaureate? Three structuring tensions of the early years (1962-1973). Journal of Research in International Education, 8(3), 235-261.

Tarc, P. (2019). Internationalization of education as an emerging field? A framing of international education for cross-domain analyses. Policy Futures in Education, 17(6), 732-744.

Thompson, J. (1998). Towards a model for international education. In J. Thompson \& M. C. Hayden (Eds.), International education: Principles and practice (pp. 276-290). Oxford: Routledge.

Thornton, P. H., \& Ocasio, W. (2013). Institutional logics. In L. L. Putnam \& D. K. Mumby (Eds.), The SAGE handbook of organizational communication: Advances in theory, research, and methods (pp. 99-129). New York, NY: Sage.

Thornton, P. H., Ocasio, W., \& Lounsbury, M. (2012). The institutional logics perspective: A new approach to culture, structure, and process. Oxford: Oxford University Press.

van Oord, L. (2007). To westernize the nations? An analysis of the International Baccalaureate's philosophy of education. Cambridge Journal of Education, 37(3), 375-390.

Vavrus, F., \& Bartlett, L. (2006). Comparatively knowing: Making a case for the vertical case study. Current Issues in Comparative Education, 8(2), 95-103.

Vavrus, F., \& Bartlett, L. (2012). Comparative pedagogies and epistemological diversity: Social and materials contexts of teaching in Tanzania. Comparative Education Review, 56(4), 634-658.

Wang, Y. W., Davidson, M. M., Yakushko, O. F., Savoy, H. B., Tan, J. A., \& Bleier, J. K. (2003). The scale of ethnocultural empathy: Development, validation, and reliability. Journal of Counseling Psychology, $50(2), 221$.

Weenink, D. (2009). Creating a niche in the education market: The rise of internationalised secondary education in the Netherlands. Journal of Education Policy, 24(4), 495-511.

Wilkinson, V., \& Hayden, M. (2010). The international baccalaureate diploma and student attitudes: An exploratory study. Journal of Research in International Education, 9(1), 85-96.

Wright, E., Lee, M., Tang, H., \& Chak Pong Tsui, G. (2016). Why offer the International Baccalaureate Middle Years Programme? A comparison between schools in Asia-Pacific and other regions. Journal of Research in International Education, 15(1), 3-17.

Yemini, M., \& Dvir, Y. (2016). International Baccalaureate as a litmus test revealing conflicting values and power relations in the Israeli education system. Discourse: Studies in the Cultural Politics of Education, 37(2), 310-323.

Publisher's Note Springer Nature remains neutral with regard to jurisdictional claims in published maps and institutional affiliations.

Karen Parish is an associate professor at the Faculty of Education, Inland Norway University of Applied Sciences. Karen works in the field of comparative and international education and her research interests include human rights, inclusive education, school choice. and the private international schooling sector. 